\title{
INCENTIVOS À PRODUÇÃO DE FRUTAS E AS MUDANÇAS NA AGRICULTURA DA REGIÃO NORTE DO ESTADO DO RIO DE JANEIRO ${ }^{1}$
}

\author{
DOUGLAS VIANNA BAHIENSE ${ }^{2}$, PAULO MARCELO DE SOUZA ${ }^{3}$, NIRALDO JOSÉ PONCIANO ${ }^{4}$
}

RESUMO - A economia agrícola da região Norte Fluminense é, historicamente, dependente da atividade sucroalcooleira. Na tentativa de reduzir tal dependência, vêm sendo adotados incentivos ao desenvolvimento da fruticultura na região, particularmente através do "Programa Frutificar". O presente trabalho visa a avaliar os impactos desse programa, sob a ótica de sua contribuição para elevar a produção de frutas e diversificar a agricultura regional. A análise foi efetuada mediante o emprego do modelo shift-share, de taxas geométricas de crescimento, e do Índice de Diversificação. De mão dessas análises, pode-se concluir que foi constatada a redução da área agrícola da região, particularmente associada à queda nas áreas cultivadas com cana-deaçúcar, arroz, milho e feijão. Por outro lado, no período sob estímulo do "Programa Frutificar", verificouse aumento do cultivo das fruteiras: abacaxi, banana e coco-da-baía. Esta constatação é um indicativo da contribuição da fruticultura como fator de diversificação da economia agrícola regional. Cabe ressaltar que a economia da região Norte Fluminense é ainda fortemente dependente do setor sucroalcooleiro.

Termos para indexação: economia; fruticultura; diversificação.

\section{INCENTIVES TO FRUIT PRODUCTION AND AGRICULTURAL CHANGES IN THE NORTHERN REGION OF RIO DE JANEIRO}

\begin{abstract}
The agricultural economy of the North region of Rio de Janeiro is historically dependent on sugarcane production. In an attempt to reduce such dependence, incentives for the development of fruit production in the region have been adopted, particularly through the "Frutificar" Program (Bear fruit Program). This research aims to evaluate the impacts of the mentioned program, especially its contribution to increase the fruits production and raise the diversification of regional agriculture. The analysis was performed by using the shift-share model, geometric rates of growth and the Diversification Index. It was observed reduction in agricultural area of the region, particularly associated with the fall in areas cultivated with sugar cane, rice, corn and beans. In the period of the "Frutificar" Program incentives, there were an increase in the production of pineapple, banana and coconut, which contributed to the diversification of the regional agricultural economy. However, this economy still remains heavily dependent on sugarcane. Index terms: economy; fruit production; diversification.
\end{abstract}

${ }^{1}$ (Trabalho 096-14). Recebido em: 27-03-2014. Aceito para publicação em:17-10-2014.

${ }^{2}$ M. Sc. Produção Vegetal na Universidade Estadual Norte Fluminense Darcy Ribeiro - UENF/ Laboratório de Engenharia Agrícola/ Av. Alberto Lamego, 2000 - Horto, Campos dos Goytacazes-RJ.E- mail: douglas.bahiense@yahoo.com.br

${ }^{3}$ D. Sc. Economia Rural na Universidade Federal de Viçosa - UFV/Professor Associado da Universidade Estadual do Norte Fluminense - UENF, Laboratório de Engenharia Agrícola/ Av. Alberto Lamego, 2000 - Horto, Campos dos Goytacazes-RJ. E-mail: pmsouza@ uenf.br

${ }^{4}$ D. Sc. Economia Rural na Universidade Federal de Viçosa - UFV/Professor Associado da Universidade Estadual do Norte Fluminense - UENF, Laboratório de Engenharia Agrícola/ Av. Alberto Lamego, 2000 - Horto, Campos dos Goytacazes.E-mail: njponciano@ gmail.com 


\section{INTRODUÇÃO}

O Norte Fluminense apresenta forte característica rural, quadro em parte alterado pelo crescimento da atividade petrolífera e dos royalties a ela associados (MARAFON, 2011). Historicamente, o setor agropecuário da região tem sido caracterizado por alta concentração fundiária e por índices de produtividade baixos em relação aos valores nacionais (SOUZA; FELIPE JÚNIOR, 2012).

Uma das principais atividades econômicas da região é a indústria sucroalcooleira (BURLA et al., 2012), atividade que, desde o século XVII, é preponderante na região (RIBEIRO, 2011). Porém, em virtude de mudanças político-institucionais e nas condições de mercado, que afetaram o setor sucroalcooleiro, a economia agrícola da região tem experimentado um processo de empobrecimento, associado a indicadores de êxodo rural, degradação ambiental e baixos índices de desenvolvimento humano (BURLA et al., 2012).

Essa situação está particularmente associada à nova realidade da atividade sucroalcooleira, marcada pela desregulamentação e pela abertura do mercado, que se contrapõe à forte intervenção estatal que predominou no passado. Nessa fase de desregulamentação, ocorreu, nos anos 90 até 2009, um cenário de rearranjo da agroindústria canavieira, quando os produtores tiveram de adaptar-se ao livre mercado e produzir sem os subsídios, incentivos e coordenação estatal até então existentes (SOARES; RIBEIRO, 2013).

Incapaz de adaptar-se totalmente a esse contexto, o setor sucroalcooleiro da região Norte Fluminense passou a sofrer sucessivas crises. Nas décadas de 80 e 90 , em virtude do encerramento das atividades em várias unidades industriais, o setor diminuiu seu tamanho e importância, com reflexos econômicos e sociais negativos para toda a região (CASTRO; RIBEIRO, 2010).

Nesse cenário, são necessárias alternativas de cultivo capazes de contribuir para a retomada do desenvolvimento rural na região. Dentre elas, a fruticultura vem sendo apontada como uma opção viável (GOMES FILHO et al., 2010). Essa atividade apresenta-se como alternativa para os produtores da região, cujas condições edafoclimáticas se mostram propícias ao cultivo de frutas. Além disso, a região está próxima dos grandes centros consumidores da região Sudeste, o que facilita a comercialização e tende a incrementar os ganhos com os produtos vendidos (PESSANHA et al., 2010).

Apesar das evidências acerca do potencial e do incipiente avanço da fruticultura na região, sabe- se que uma série de fatores, de ordem tecnológica ou político-institucional, pode contribuir para alavancar ou estagnar o processo de desenvolvimento regional de uma determinada atividade. Embora o setor privado seja o motor do desenvolvimento, por meio de investimentos em empreendimentos rentáveis, assumindo riscos e gerando riquezas, cabe ao setor público criar as condições necessárias para impulsionar o desenvolvimento, principalmente para o agricultor familiar (SOUZA; PAULO; PONCIANO, 2011).

Parte dessas condições surgiu com o advento do Programa Frutificar, criado pelo Governo do Estado no ano de 2000, com a finalidade de promover a diversificação agrícola e elevar a oferta de empregos, através do financiamento para investimento e custeio de lavouras frutícolas, integradas a plantas industriais (RIO DE JANEIRO, 2000). O programa foi constituído com três pilares básicos: a integração entre a produção e a indústria processadora da fruta; a concessão de empréstimos com juros subsidiados para financiar o projeto, e a obrigatoriedade da irrigação por causa da irregularidade de chuvas na região (FRAGA, 2005). Com uma linha de crédito específica do Sistema Moeda Verde, vinculado ao Fundo de Desenvolvimento Econômico e Social, o programa passou a liberar crédito a agricultores para produzir as frutas como abacaxi, maracujá e goiaba, dentre outras (SOUZA; FELIPE JÚNIOR, 2012).

O objetivo foi avaliar se os incentivos concedidos pelo Programa Frutificar promoveram mudanças no perfil da agricultura regional, incrementando a produção de frutas.

\section{MATERIAL E MÉTODOS}

\section{Modelo shift-share}

Para analisar os possíveis efeitos do Programa Frutificar sobre a produção agrícola da região norte do Rio de Janeiro, foi empregado o modelo shift-share, na forma proposta por Yokoyama, Igreja e Neves (1989). Esse modelo baseia-se na decomposição da mudança da área de determinada cultura nos efeitos escala e substituição. Conforme o modelo, a variação da área total ocupada por um produto $\mathrm{j}$ qualquer, ocorrida no intervalo de tempo compreendido entre $t=0$ e $t=T$, pode ser representada pela expressão:

$$
A_{j T}-A_{j 0}
$$

A expressão (2), que nada mais é do que outra forma de escrever a expressão (1), mediante o uso do coeficiente $\gamma$, possibilita compor a variação da área em dois efeitos: 


$$
A_{j T}-A_{j 0}=\left(\gamma A_{j 0}-A_{j 0}\right)+\left(A_{j T} \gamma A_{j 0}\right)
$$

Em que: hectares,

$\left(\gamma A_{j 0}-A_{j 0}\right)=$ Efeito escala, expresso em hectares.

$\left(A_{j T}-\gamma A_{j 0}\right)=$ Efeito substituição, expresso em

Em (2), $\gamma$ é o coeficiente que mede a modificação na área total cultivada (AT) com todos os produtos considerados na análise (dimensão do sistema) entre os períodos inicial $(\mathrm{t}=0)$ e final $(\mathrm{t}=\mathrm{T})$, sendo ele obtido por:

$$
\gamma=A T_{T} / A T_{0}
$$

$\mathrm{O}$ efeito escala refere-se à parte daquela mudança que esteve associada à alteração do tamanho do sistema produtivo regional (soma das áreas de todas as culturas): se o sistema se expandiu, a cultura também se beneficiou, com efeito escala positivo; do contrário, o efeito escala é negativo. Já o efeito substituição, que independe das mudança no tamanho do sistema agrícola regional, pode ser negativo, quando a cultura é substituída por outra, ou positivo, quando ela tomou área de outras culturas no sistema.

Uma vez que no sistema de produção somente se verifica o efeito escala, a soma dos efeitos substituição deve ser nula, ou seja:

$$
\sum_{j=1}^{\mathrm{n}}\left(\mathrm{A}_{j \mathrm{~T}}-\gamma A_{j 0}\right)=0
$$

Descritas as mudanças na área dos produtos selecionados, procurou-se também verificar em que intensidade elas impactaram a produção. Para tanto, foram calculadas as taxas médias anuais de crescimento da produção de cada cultura $\left(r_{Q}\right)$. Esse crescimento resulta da soma de dois efeitos: o efeito área, expresso pela taxa de crescimento da área $\left(r_{A}\right)$, e o efeito rendimento ou produtividade, medido pela taxa de crescimento da produtividade $\left(r_{R}\right)$. Essas taxas, em percentagem ao ano, foram estimadas pelas expressões:

$$
\begin{aligned}
& r_{A j}=\left(\sqrt[T]{\frac{A_{j T}}{A_{j 0}}}-1\right) \times 100 \\
& r_{R_{j}}=\left(\sqrt[T]{\frac{R_{j T}}{R_{j 0}}}-1\right) \times 100 \\
& r_{Q_{j}}=\left(\sqrt[T]{\frac{Q_{j I}}{Q_{j 0}}}-1\right) \times 100
\end{aligned}
$$

E em que, para $t$ variando entre os anos inicial $t=0$ e final $t=T$ : instante $\mathrm{t}$

$\mathrm{A}_{\mathrm{jt}}=$ área cultivada do j-ésimo produto no instante $\mathrm{t}$;

$\mathrm{R}_{\mathrm{jt}}=$ rendimento do j-ésimo produto no instante t;

$\mathrm{Q}_{\mathrm{jt}}=$ produção total do j-ésimo produto no

\section{Índice de diversificação}

Para sintetizar as mudanças ocorridas no sistema produtivo da região, foi calculado, ainda, o Índice de Diversificação $(D)$. No presente contexto, esse índice foi calculado a partir das participações de cada produto $i$ na área total e no valor da produção do sistema do estado, em cada ano $t\left(S_{i t}\right)$, mediante a expressão proposta por Gasques et al. (2010):

$$
D=\frac{1}{\sum S_{2}^{2}}
$$

Esse índice, cujo menor valor é um (caso hipotético de uma região que cultive um único produto), cresce à medida que aumenta a diversificação dos cultivos.

\section{Variáveis e fonte de dados}

As informações relativas à produção e à área colhida dos produtos, para a região Norte Fluminense, foram extraídas das estatísticas publicadas pela Fundação Instituto Brasileiro de Geografia e Estatística - FIBGE, constantes do Sistema IBGE de Recuperação Automática - SIDRA (2014).

A escolha das atividades analisadas baseou-se na importância relativa de cada produto na área total ocupada com culturas permanentes e temporárias, bem como no valor total da produção dessas culturas. Com esse critério, foram selecionas as culturas de abacaxi, arroz, banana, batata-doce, café, canade-açúcar, coco-da-baía, feijão, goiaba, laranja, mandioca, manga, maracujá, melancia, melão, milho, tomate e urucum. Durante o período analisado, a participação média desse conjunto de culturas na área e no valor da produção total das culturas (temporárias + permanentes) foi superior a $99 \%$.

Após a seleção das culturas, as variações na área, na produção e na produtividade foram analisadas através do modelo shift-share, considerando-se dois períodos: (1) que caracteriza a fase anterior ao Programa Frutificar, de 1990 a 2000, e (2) fase de vigência deste programa, de 2000 a 2012. Na separação desses dois períodos, foi considerado marco divisor o ano de 2000 (criação do programa), 
sob a hipótese de que os possíveis efeitos de seus estímulos sobre a produção só ocorreriam a partir dos anos seguintes.

\section{RESULTADOS E DISCUSSÃO}

No decorrer da década anterior à implantação do Programa Frutificar, o efeito escala foi negativo (Tabela 1). Isso resulta da redução da área total do sistema produtivo composto pelas culturas analisadas, com cerca de 46.160 ha de decréscimo no período.

As culturas que mais perderam área foram cana-de-açúcar, arroz, feijão e milho. Também as culturas de café, maracujá, laranja, banana, batatadoce, tomate e manga sofreram redução na área, porém em menor intensidade.

Como o efeito escala do período foi negativo, apenas aquelas culturas com efeito substituição positivo, e em magnitude suficiente para superar o efeito escala, exibiram crescimento na área cultivada. Esse foi o caso apenas de abacaxi, coco-da-baía, goiaba, mandioca, melão, melancia e urucum. No caso da banana, o efeito substituição positivo não foi suficiente para compensar o efeito escala.

Essas culturas, especialmente a mandioca, beneficiaram-se da ocupação de terras antes destinadas a outros produtos, particularmente de arroz, feijão e cana-de-açúcar, que foram as que mais perderam área no processo de substituição. Juntas, estas três culturas responderam por cerca de $88 \%$ da área cedida no processo de substituição. Além delas, também foram substituídas no sistema: café, milho, laranja e maracujá, além de batata-doce, manga e tomate

Os produtos coco-da-baía, urucum, melancia, melão e goiaba exibiram forte crescimento da produção, que se elevou a taxas médias anuais na faixa de 26 a $66 \%$. Na maior parte dos casos, a principal fonte desse crescimento foi a expansão da área plantada, ainda que o rendimento também tenhase elevado no período (exceto para urucum). No caso de melão, o aumento da produtividade foi a principal fonte de explicação do crescimento da produção.

Houve ainda crescimento da produção de abacaxi, mandioca e cana-de-açúcar, além de milho, com taxa menos expressiva. No caso destas duas últimas culturas, que sofreram redução de área no período, a produção elevou-se pelo aumento da produtividade. Nos dois outros casos, o efeito do aumento de produtividade foi menos importante, como no abacaxi, ou mesmo negativo, como na mandioca, e o aumento da área foi a principal fonte de crescimento da produção.
Nas outras culturas, houve queda na produção. Esse processo deu-se com mais intensidade nas culturas de feijão, laranja, maracujá, batata-doce e arroz, cujas produções declinaram a taxas anuais médias na faixa de 5-9\%, e, sobretudo, no café, com queda de $12,5 \%$ ao ano na quantidade produzida.

Em geral, a queda na produção foi causada pela redução da área, já que as taxas de variação na produtividade dessas culturas, num sentido ou em outro, tiveram efeito menor. Apenas nos casos de banana e maracujá o efeito da queda na produtividade foi um pouco maior do que o efeito da redução da área.

Os resultados da análise do período de vigência do Programa Frutificar encontram-se na Tabela 2. Tal como na década anterior, o efeito escala desse período foi negativo. Porém, a queda na área do sistema foi menor, equivalente a uma redução de 36.371 hectares.

O produto com maior perda de área no período foi cana-de-açúcar. Também sofreram redução significativa na área os produtos milho, arroz, feijão, maracujá, banana e urucum. Além do efeito escala do período, que foi negativo, essas culturas (exceto banana) foram substituídas no sistema por outras atividades. Esse processo beneficiou particularmente as culturas de mandioca, abacaxi e coco-da-baía, que incorporaram a seus cultivos cerca de $98 \%$ da área deixada pelas culturas substituídas no sistema. Não por acaso, essas foram as culturas com maior incremento na área cultivada no período.

Neste período, houve crescimento expressivo na produção de abacaxi e melancia, com taxas médias anuais de 19,2 e 11,7\%, além de coco-da-baía, manga e mandioca, com taxas médias de 9,$6 ; 8,8$ e 7,7\%, respectivamente. Exceto a cultura de melancia, cuja produção se elevou com base no aumento da produtividade, nos demais casos, as altas taxas de crescimento da produção atribuem-se ao aumento da área plantada, já que os rendimentos declinaram no período. Também as culturas de goiaba e café apresentaram taxas positivas de crescimento nesse período, associadas ao aumento da área plantada, no primeiro caso, e ao crescimento da produtividade, no segundo.

Por outro lado, o período foi marcado por queda na produção das demais culturas analisadas. A maior queda ocorreu na produção de urucum, que declinou a uma taxa média de $28 \%$ ao ano. Essa queda foi também elevada, na faixa de $10-20 \%$ ao ano, para as culturas de arroz, maracujá e tomate, assim como para melão e milho, com quedas da ordem de $5-10 \%$. Também a produção de laranja, cana-de-açúcar, batata-doce e feijão caiu a taxas 
significativas, da ordem de 2-4\%, enquanto o declínio da produção de banana foi menos expressivo. $\mathrm{Na}$ maior parte dos casos, a queda na produção esteve associada à redução na área plantada, uma vez que os rendimentos, de modo geral, elevaram-se no período. As exceções ficam por conta de arroz, tomate e maracujá, nos quais houve, além de queda na área, queda na produtividade.

Sobre as mudanças ocorridas, destaca-se que algumas culturas tradicionalmente desenvolvidas na região, como é o caso de arroz, mandioca, milho e, em alguma medida, café, já vinham perdendo espaço no sistema produtivo regional, nas décadas de $70 \mathrm{e}$ 80, como demonstrado por Souza e Ponciano (2006). Esse processo esteve particularmente associado à forte expansão da área com cana-de-açúcar, promovida pelos fortes subsídios a sua produção nesse período, como relatado por Cruz (2004).

Nas décadas aqui estudadas, já num cenário de desregulamentação do setor sucroalcooleiro, com redução dos estímulos do Programa Nacional do Álcool (Pró-Álcool), a partir de meados dos anos 80, e extinção do Instituto do Açúcar e do Álcool (IAA), na década de noventa, nota-se forte retração da área cultivada com cana-de-açúcar. Dívidas contraídas no período anterior, baixa produtividade, em parte associada ao déficit hídrico regional, e elevados custos de produção são fatores que contribuíram para reduzir a dimensão desse setor na região. Por outro lado, os ganhos de produtividade observados, principalmente na década de noventa (Tabela 1), são indícios de que essas transformações resultaram num setor menor do que no passado, porém mais moderno e competitivo, como afirma Cruz (2004).

A cultura de mandioca, no passado deslocada pela expansão da cana, voltou a expandir-se na região. Porém esse crescimento, alicerçado em preços favoráveis e menores gastos com insumos, vem dando-se apenas pelo crescimento da área, sem ganhos de produtividade. Já com as culturas de arroz, milho e café, essa retomada não ocorreu. As áreas dessas culturas continuaram a cair no período aqui analisado, fato também observado para a cultura do feijão.

O declínio dessas culturas não é um fenômeno restrito à região estudada. Trata-se de um processo atrelado ao predomínio do cultivo mecanizado e em grande escala desses produtos em outras regiões, com destaque para o Centro-Oeste. A produção obtida em cultivos tradicionais, pouco produtivos e intensivos em mão de obra, como é o presente caso, não consegue competir com a produção gerada naquelas regiões, de maior produtividade, menor gasto com mão de obra e custo unitário mais baixo.

Não por acaso, a fruticultura, onde a mecanização de todas as etapas de cultivo encontra limitações e maior é o peso da mão de obra, vem encontrando espaço na região. Isso vem ocorrendo especialmente com abacaxi e coco-da-baía, que experimentaram crescimento expressivo na área cultivada, mas também com goiaba, melancia e manga (esta apenas no último período). Em que pesem outros fatores favoráveis (preços, condições edafoclimáticas, distância de centros consumidores, etc.), a expansão dessas culturas beneficiou-se dos recursos liberados pela retração da atividade canavieira, especialmente terra e mão de obra. Tanto é que, com exceção de abacaxi e manga, as maiores taxas de crescimento da área e da produção ocorreram na década de noventa, paralelamente ao declínio da produção de cana, e antes mesmo dos incentivos governamentais.

Por outro lado, essas são, basicamente, as frutíferas que vêm recebendo financiamentos do Frutificar na região (Informação pessoal) ${ }^{1}$. Sem esses incentivos, as demais frutíferas (banana, laranja e maracujá, com produção em queda durante todo o período, e melão, com queda na última década) não tiveram o mesmo desempenho. Dentre elas, apenas maracujá recebeu parcela significativa de recursos do Programa em sua fase inicial. Porém, a produtividade dessa cultura na região tem sido afetada por problemas de manejo de irrigação, incidência de ataques de doenças e de pragas, baixo conhecimento na utilização de defensivos e manejo inadequado da polinização artificial (PONCIANO; SOUZA; GOLYNSKI, 2006). Além disso, aspectos como erros na implantação dos projetos, subestimativas de custos e superestimativas de produtividade, atraso no recebimento das mudas, falta de assistência técnica adequada, dentre outros, são apontados como justificativas para o abandono das lavouras de maracujá na região (ERBAS, 2003).

Observa-se na Figura 1 que, em decorrência das mudanças ocorridas, as culturas de arroz, milho e feijão, cujas áreas tinham alguma representatividade na região, perderam essa importância no decorrer das duas décadas analisadas. Já as culturas de banana e mandioca, tradicionalmente cultivadas na região, elevaram sua participação no sistema. Por outro lado, abacaxi e coco, culturas de pouca expressão no ano inicial do estudo, passam, ao final do período, a representar conjuntamente cerca de $5 \%$ da área do sistema.

Porém, essas alterações não afetaram drasticamente a composição da produção agrícola

Ronaldo Soares Pinto, gerente executivo do Programa, em 2013. 
na região Norte Fluminense, fortemente calcada na produção de cana-de-açúcar. Embora tenha ocorrido redução da participação da cana-de-açúcar na área cultivada, esta cultura encerra o período respondendo por mais de $80 \%$ da área do sistema produtivo considerado. Reflexo dessa situação são os baixos índices de diversificação da área agrícola regional, exibidos na segunda coluna da Tabela 3 . Esses valores, que estão próximos da unidade, valor mínimo assumido pelo índice, elevaram-se um pouco no período, porém não o suficiente para mudar o perfil altamente concentrado da distribuição da área agrícola regional entre os cultivos.

Ou seja, há necessidade de contornar algumas dificuldades para que o desenvolvimento da fruticultura promova mudanças maiores na economia agrícola regional. Nesse sentido, Souza, Paulo e Ponciano (2010) ressaltam que a fruticultura requer um conjunto de habilidades, cuidados que, numa região tradicionalmente dedicada a outras atividades, precisam ser desenvolvidos. Trata-se de uma atividade extremamente exigente em termos técnicos, desde o cultivo até a pós-colheita. Aspectos como deficiência no controle fitossanitário e pouca pesquisa quanto a variedades, tecnologia de produção e tratamento pós-colheita são considerados entraves à produção de frutas. Problemas como o baixo nível de conhecimento dos produtores da região e a falta de tradição no cultivo de frutas, entre outros, impedem o desenvolvimento e o aumento da competitividade (NASCIMENTO; SILVA, 2005).

Porém, uma vez que a fruticultura se destaca por apresentar maior valor agregado por área, o índice de diversificação do valor da produção é mais elevado. Esse índice, que declinou entre 1990 e 2000, cresceu na década seguinte, possivelmente em decorrência da fruticultura. Portanto, observa-se que, em alguma medida, o quadro de forte dependência da economia agrícola regional em relação à canade-açúcar, acentuada na década de noventa, vem alterando-se com o crescimento da importância de algumas novas atividades, particularmente dos cultivos de coco e abacaxi.

TABELA 1 - Decomposição da variação da área (efeitos escala e substituição), em ha, e da taxa de crescimento da produção (efeitos 39 área e rendimento), em \%, das principais culturas na mesorregião norte do Rio de Janeiro, período de 1990-2000.

\begin{tabular}{|c|c|c|c|c|c|c|c|}
\hline \multirow{3}{*}{ Culturas } & \multicolumn{4}{|c|}{ Variação da área } & \multirow{2}{*}{\multicolumn{3}{|c|}{ Variação da produção }} \\
\hline & \multirow{2}{*}{ Variação total } & \multicolumn{2}{|c|}{ Efeitos } & \multirow{2}{*}{$\%$} & & & \\
\hline & & Escala & Substituição & & Área & Rendim. & Total \\
\hline Abacaxi & 288,00 & $-105,47$ & 393,47 & 7,69 & 4,82 & 0,91 & 5,78 \\
\hline Arroz & $-2.365,00$ & $-821,73$ & $-1.543,27$ & $-30,16$ & $-9,56$ & 4,21 & $-5,74$ \\
\hline Banana & $-175,00$ & $-692,48$ & 517,48 & 10,11 & $-0,57$ & $-0,82$ & $-1,39$ \\
\hline Batata-doce & $-59,00$ & $-29,28$ & $-29,72$ & $-0,58$ & $-5,69$ & $-0,20$ & $-5,88$ \\
\hline Café & $-754,00$ & $-218,20$ & $-535,80$ & $-10,47$ & $-13,33$ & 0,95 & $-12,51$ \\
\hline Cana-de-açúcar & $-42.275,00$ & $-41.069,08$ & $-1.205,92$ & $-23,57$ & $-2,54$ & 6,14 & 3,44 \\
\hline Coco-da-baía & 665,00 & $-1,32$ & 666,32 & 13,02 & 60,27 & 3,85 & 66,44 \\
\hline Feijão & $-2.005,00$ & $-784,74$ & $-1.220,26$ & $-23,85$ & $-7,94$ & $-1,06$ & $-8,91$ \\
\hline Goiaba & 104,00 & $-2,86$ & 106,86 & 2,09 & 24,57 & 1,67 & 26,65 \\
\hline Laranja & $-291,00$ & $-110,09$ & $-180,91$ & $-3,54$ & $-8,35$ & 0,97 & $-7,46$ \\
\hline Mandioca & $2.008,00$ & $-815,13$ & $2.823,13$ & 55,18 & 4,43 & $-0,82$ & 3,57 \\
\hline Manga & $-32,00$ & $-14,31$ & $-17,69$ & $-0,35$ & $-6,55$ & 5,68 & $-1,25$ \\
\hline Maracujá & $-376,00$ & $-289,54$ & $-86,46$ & $-1,69$ & $-3,31$ & $-3,99$ & $-7,17$ \\
\hline Melancia & 159,00 & $-4,62$ & 163,62 & 3,20 & 23,97 & 13,83 & 41,11 \\
\hline Melão & 22,00 & $-4,84$ & 26,84 & 0,52 & 7,18 & 21,73 & 30,47 \\
\hline Milho & $-1.449,00$ & $-1155,10$ & $-293,90$ & $-5,74$ & $-3,18$ & 4,67 & 1,34 \\
\hline Tomate & $-43,00$ & $-40,73$ & $-2,27$ & $-0,04$ & $-2,61$ & $-0,19$ & $-2,79$ \\
\hline Urucum & 418,00 & $-0,44$ & 418,44 & 8,18 & 70,70 & $-3,79$ & 64,22 \\
\hline
\end{tabular}

Fonte: elaborada pelos autores, a partir de dados do IBGE (anos de 1990 e 2000). 
TABELA 2 - Decomposição da variação da área (efeitos escala e substituição), em ha, e da taxa de crescimento da produção (efeitos área e rendimento), em \%, das principais culturas na mesorregião norte do Rio de Janeiro, período de 2000-2012.

\begin{tabular}{|c|c|c|c|c|c|c|c|}
\hline \multirow{3}{*}{ Culturas } & \multicolumn{4}{|c|}{ Variação da área } & \multirow{2}{*}{\multicolumn{3}{|c|}{ Variação da produção }} \\
\hline & \multirow{2}{*}{$\begin{array}{l}\text { Variação } \\
\text { total }\end{array}$} & \multicolumn{2}{|c|}{ Efeitos } & \multirow{2}{*}{$\%$} & & & \\
\hline & & Escala & Substituição & & Área & Rendim. & Total \\
\hline Abacaxi & $3.758,00$ & $-170,64$ & $3.928,64$ & 29,60 & 19,42 & $-0,19$ & 19,19 \\
\hline Arroz & $-892,00$ & $-304,13$ & $-587,87$ & $-4,43$ & $-10,03$ & $-2,57$ & $-12,34$ \\
\hline Banana & $-632,00$ & $-660,76$ & 28,76 & 0,22 & $-2,36$ & 1,57 & $-0,83$ \\
\hline Batata-doce & $-19,00$ & $-16,46$ & $-2,54$ & $-0,02$ & $-2,92$ & 0,00 & $-2,92$ \\
\hline Café & $-132,00$ & $-52,73$ & $-79,27$ & $-0,60$ & $-7,82$ & 8,98 & 0,46 \\
\hline Cana-de-açúcar & $-41.415,00$ & $-32.091,40$ & $-9.323,60$ & $-70,25$ & $-3,33$ & 0,75 & $-2,61$ \\
\hline Coco-da-baía & $1.193,00$ & $-149,28$ & $1.342,28$ & 10,11 & 10,76 & $-1,07$ & 9,57 \\
\hline Feijão & $-738,00$ & $-346,84$ & $-391,16$ & $-2,95$ & $-6,21$ & 2,88 & $-3,51$ \\
\hline Goiaba & 42,00 & $-26,03$ & 68,03 & 0,51 & 3,11 & $-2,00$ & 1,05 \\
\hline Laranja & $-87,00$ & $-46,50$ & $-40,50$ & $-0,31$ & $-5,24$ & 3,15 & $-2,25$ \\
\hline Mandioca & $6.475,00$ & $-1.270,35$ & $7.745,35$ & 58,36 & 7,87 & $-0,14$ & 7,72 \\
\hline Manga & 82,00 & $-7,34$ & 89,34 & 0,67 & 13,30 & $-3,97$ & 8,80 \\
\hline Maracujá & $-803,00$ & $-208,91$ & $-594,09$ & $-4,48$ & $-17,57$ & $-1,28$ & $-18,62$ \\
\hline Melancia & 30,00 & $-40,05$ & 70,05 & 0,53 & 1,55 & 10,03 & 11,74 \\
\hline Melão & $-31,00$ & $-9,79$ & $-21,21$ & $-0,16$ & $-11,48$ & 6,33 & $-5,87$ \\
\hline Milho & $-2.722,00$ & $-844,75$ & $-1.877,25$ & $-14,14$ & $-11,86$ & 4,02 & $-8,31$ \\
\hline Tomate & $-70,00$ & $-31,59$ & $-38,41$ & $-0,29$ & $-6,57$ & $-5,71$ & $-11,90$ \\
\hline Urucum & $-410,00$ & $-93,44$ & $-316,56$ & $-2,39$ & $-31,19$ & 4,61 & $-28,01$ \\
\hline
\end{tabular}

Fonte: elaborada pelos autores, a partir de dados do IBGE (anos de 2000 e 2012).

TABELA 3 - Índice de diversificação do sistema de produção composto pelas principais culturas da região norte do Estado do Rio de Janeiro, segundo os critérios área e valor da produção.

\begin{tabular}{ccc}
\hline \multirow{2}{*}{ Ano } & \multicolumn{3}{c}{ Índice de diversificação } \\
\cline { 2 - 3 } & Área & Valor da produção \\
\hline 1990 & 1,26 & 2,75 \\
2000 & 1,28 & 1,73 \\
2012 & 1,50 & 3,00 \\
\hline Fonte: elaborada pelos autores, a partir de dados do IBGE (anos de 1990, 2000 e 2012).
\end{tabular}

Fonte: elaborada pelos autores, a partir de dados do IBGE (anos de 1990, 2000 e 2012).

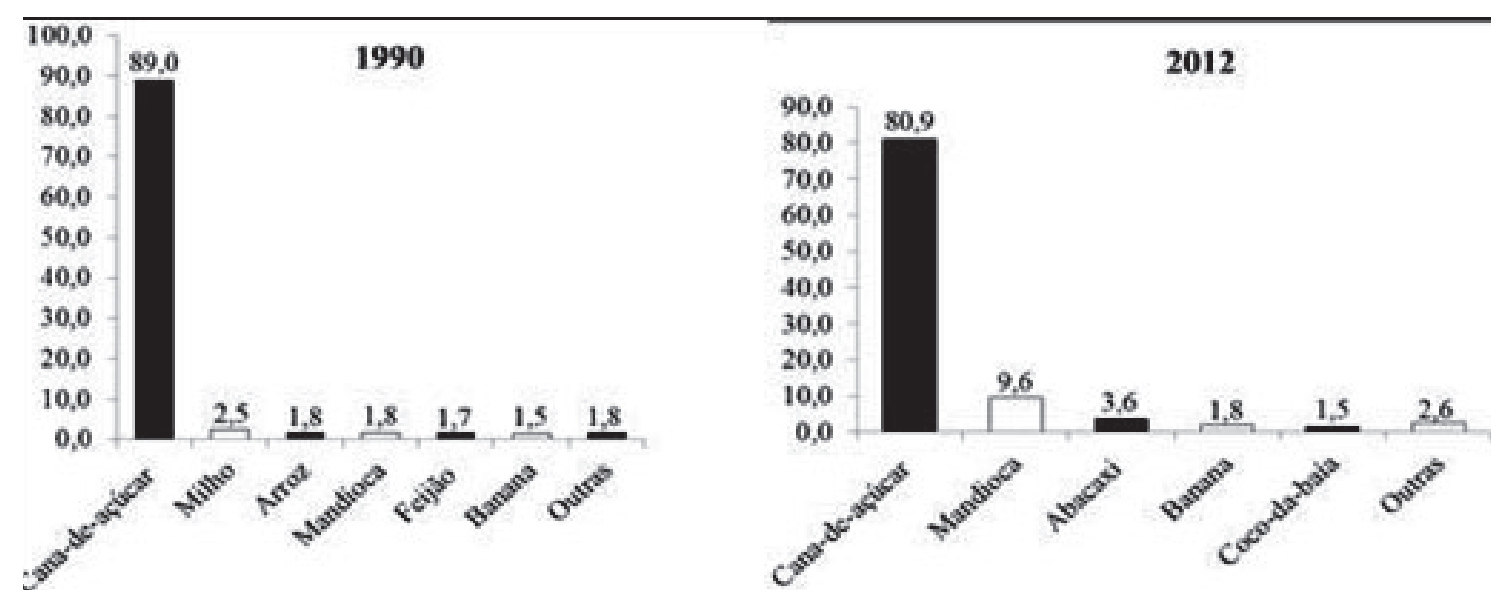

Fonte: elaborada pelos autores/dados de IBGE (anos de 1990 e 2012)

FIGURA 1 - Participação das principais culturas na área cultivada da região Norte Fluminense, anos de 1990 e 2012. 


\section{CONCLUSÕES}

A agricultura Norte Fluminense tem reduzido a dimensão de sua área agrícola, processo associado ao declínio da área cultivada com alguns produtos tradicionais da região, especialmente cana-de-açúcar, milho, arroz e feijão. Observou-se, porém, expressivo crescimento de algumas frutíferas, com destaque para as culturas de abacaxi e coco-da-baía, devido à magnitude da área que representam, além de manga, goiaba e melancia.

Parte desse crescimento deu-se na década de noventa, paralelamente à forte retração do cultivo da cana-de-açúcar na região, e anteriormente ao advento do Programa Frutificar. Recursos antes investidos na produção de cana, em especial terra e mão de obra, tornaram-se disponíveis com o declínio desta atividade e encontraram na fruticultura uma alternativa de aplicação. Por outro lado, não deve ser desprezada a provável contribuição dos financiamentos do Frutificar para a manutenção e elevação (caso do abacaxi) das taxas do crescimento da produção dessas frutíferas na década seguinte. Não foi possível, entretanto, aferir a magnitude dessa contribuição.

Uma importante consequência desse processo foi a melhoria dos índices de diversificação da economia regional. De todo modo, os resultados evidenciaram que a economia agrícola regional mantém-se pouco diversificada e fortemente dependente da cana-de-açúcar. O apoio a investimentos na fruticultura, aliado à assistência técnica e a melhores práticas de gerenciamento, pode contribuir para melhorar esse quadro. Ressalta-se, portanto, a necessidade de melhores níveis técnicos, de planejamento e de gestão, em todas as etapas de seleção, implantação e condução dos projetos, visando a maximizar os resultados e a contribuir, efetivamente, com o avanço da fruticultura na região.

Encerrando, há que se destacar algumas limitações do estudo. Uma delas decorre da própria metodologia, que permite decompor as mudanças na produção, mas não explicá-las. A carência de estudos regionais sobre o tema agrava essa falta. Outra é a impossibilidade de distinguir o efeito dos incentivos concedidos do efeito de outros eventos que podem ter contribuído para o comportamento das culturas analisadas. Finalmente, há que se destacar que as conclusões do estudo se basearam em comparações pontuais entre anos extremos das décadas. Os impactos de eventos climáticos, ou mesmo do ataque de pragas e doenças, podem afetar de modo diferenciado as culturas num determinado ano, sem que isso implique uma tendência prevalecente no período.

\section{REFERÊNCIAS}

BURLA, R. S.; SILVANETO, R.; WERNECK, L. G.; MACIEL, C. P.; SILVA, R. A.; PESSANHA, H. M.; OLIVEIRA, V. de P. S.; Análise das condicionantes socioeconômicas e ambientais para a implantação da silvicultura nas regiões Norte e Noroeste Fluminense.

Boletim do Observatório Ambiental Alberto Ribeiro Lamego, Campos dos Goytacazes, v. 6, n. 1, p. 85-113, 2012.

CASTRO, R. A. R.; RIBEIRO, A. C. Relações de cooperação no aglomerado sucroalcooleiro fluminense: reflexões sobre o papel do recurso intangível no desenvolvimento regional. Agenda Social, Campos Dos Goytacazes, v. 4, n. 2, p.59-75, 2010.

CRUZ, J. L. V. Modernização produtiva, crescimento econômico e pobreza no Norte Fluminense (19702000). In: PESSANHA, R. M.;SILVA NETO, R. (Org.) Economia e desenvolvimento no Norte Fluminense: da cana de açúcar aos royalties do petróleo. Campos dos Goytacazes: WTC Editor, 2004. 364 p.

ERBAS, M. S. A reestruturação do setor agrícola: a luta pela hegemonia político-econômico no município de Campos dos Goytacazes. In: CONGRESSO BRASILEIRO DE SOCIOLOGIA, 11., 2003, Campinas. Anais... Campinas: UNICAMP, 2003. p $1-42$.

FRAGA, R. R. de O. Sustentabilidade Rural e Políticas Públicas - A Reestruturação Produtiva da Região Canavieira do Norte Fluminense. In: ENCONTRO DE GEÓGRAFOS DA AMÉRICA LATINA, 10., 2005, São Paulo. Anais... São Paulo: USP, 2005. p.5388-5408.

GASQUES, J.G.; BASTOS, E.T.; BACCHI, M.R.P.; VALDES, C. Produtividade total dos fatores e transformações da agricultura brasileira: análise dos dados dos censos agropecuários. In: CONGRESSO DA SOCIEDADE BRASILEIRA DE ECONOMIA, ADMINISTRAÇÃO E SOCIOLOGIA RURAL, 48., Campo Grande, 2010. Anais... Brasília: SOBER, 2010. 
GOMES FILHO, A.; OLIVEIRA, J. G. de; VIANA, A. P.; SIQUEIRA, A. P. de O.; OLIVEIRA, M. G.; PEREIRA, M. G. Marcadores moleculares RAPD e descritores morfológicos na avaliação da diversidade genética de goiabeiras (Psidiumguajava L.). Acta Scientiarum. Agronomy, Maringá, v.32, n.4, out./ dez. 2010, 21p.

INSITUTO BRASILEIRO DE GEOGRAFIA E ESTATÍSTICA - IBGE. Sistema IBGE de Recuperação Automática 2014, Disponível em: $<$ http://www.sidra.ibge.gov.br/bda/tabela/protabl. asp? $\mathrm{c}=1613 \& \mathrm{z}=\mathrm{t} \& \mathrm{o}=11 \& \mathrm{i}=\mathrm{P}>$. Acesso em: $10 \mathrm{fev}$. 2014.

MARAFON, G. J. Principais transformações em curso no espaço rural na atualidade. Revista Geográfica de América Central, Heredia, p.84-99, 2011. Número Especial

NASCIMENTO, D.C.O.; SILVA, R.B. Análise do processo de expansão da fruticultura na região Norte Fluminense do Estado do Rio de Janeiro. In: SEMANA DE ENGENHARIA DA UFF, 7., SEMINÁRIO FLUMINENSE DE ENGENHARIA, 4., UFF, 2005. Niterói. Anais...

PESSANHA, P. G. de O.; VIANA,A.P.; CARVALHO, A. J. C. de; OLIVEIRA, J. G. de. Teores foliares de nutrientes em doze genótipos de videira. Semina: Ciências Agrárias, Londrina, v. 31, n. 4, p. 881888, 2010.

PONCIANO, J. J.; SOUZA, P. M.; GOLYNSKI, A. Avaliação econômica da produção de maracujá (Passiflora edulis Sims $f$.) na região norte do Estado do Rio de Janeiro Revista Economia e Desenvolvimento, Santa Maria, n. 18, p. 16-32, 2006.

RIBEIRO, M. A. O papel dos centros urbanos na rede de localidades centrais fluminense: Campos dos Goytacazes, Macaé e Itaperuna - 1966/2007. Revista Geográfica de América Central, Heredia, p.1-15, 2011. Número Especial .

RIO DE JANEIRO. Decreto $\mathrm{n}^{\circ} 26.278$, de 4 de maio de 2000. Institui o programa moeda verde frutificar, cria o grupo executivo para a implementação do projeto pólo de fruticultura das regiões norte e noroeste, e dá outras providências. Diário Oficial do Estado, Rio de Janeiro, 4 maio 2000. 2p.
SOARES, R. V.; RIBEIRO, A. C. Análise do declínio do setor sucroalcooleiro na região Norte Fluminense a partir da economia institucional. In: CONGRESSO NACIONAL DE EXCELÊNCIA EM GESTÃO, 9., Rio de Janeiro, 2013. Anais... 20p.

SOUZA, P. M.; PAULO, R. M.; PONCIANO, N. J. Fatores Relevantes na Determinação das Escolhas Gerenciais e Organizativas dos Fruticultores da região Norte Fluminense. Revista IDeAS, Rio de Janeiro, v. 4, n. 2, p. 493-518, 2010.

SOUZA, P. M.; PAULO, R. M.; PONCIANO, N. J. Tecnologia na Fruticultura das regiões norte e noroeste do Estado do Rio de Janeiro. Informe Gepec, Toledo, v. 15, n. 1, p. 43-63, 2011.

SOUZA, P. M.; PONCIANO, N. J. O perfil da produção agrícola na região Norte Fluminense: uma análise das alterações ocorridas no período de 1970 a 2000. In: CARVALHO, A. M.; TOTTI, M. E. F. (Org.). Formação histórica e econômica do Norte Fluminense. Rio de Janeiro: Garamond, 2006. v. 1, p. 169-224.

SOUZA, W. F. de; FELIPE JÚNIOR, E. de S. A cadeia produtiva do abacaxi na região Norte Fluminense: um estudo de caso na localidade de correnteza. In: ENCONTRO NACIONAL DE GEÓGRAFOS, 17., 2012, Belo Horizonte. UFMG, Anais... p. 1-9.

YOKOYAMA, L. P.; IGREJA, A. C. M.; NEVES, E. M. Modelo shift-share: uma readaptação metodológica e uma aplicação para o Estado de Goiás. In: CONGRESSO BRASILEIRO DE ECONOMIA E SOCIOLOGIA RURAL, 27., Piracicaba, 1989. Anais... Brasília: SOBER, 1989. v.1, p. 63-68. 